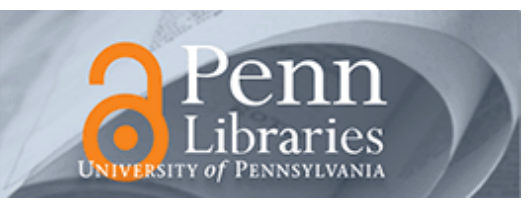

University of Pennsylvania

ScholarlyCommons

September 2007

\title{
Detection of Moisture and Methanol Gas Using a Single Electrospun Tin Oxide Nanofiber
}

\author{
Yu Wang \\ University of Pennsylvania \\ Idalia Ramos \\ University of Puerto Rico \\ Jorge J. Santiago-Aviles \\ University of Pennsylvania, santiago@seas.upenn.edu
}

Follow this and additional works at: https://repository.upenn.edu/ese_papers

\section{Recommended Citation}

Yu Wang, Idalia Ramos, and Jorge J. Santiago-Aviles, "Detection of Moisture and Methanol Gas Using a Single Electrospun Tin Oxide Nanofiber", . September 2007.

Copyright 2007 IEEE. Reprinted from IEEE Sensors Journal, Volume 7, Issue 9, September 2007, pages 1347-1348.

This material is posted here with permission of the IEEE. Such permission of the IEEE does not in any way imply IEEE endorsement of any of the University of Pennsylvania's products or services. Internal or personal use of this material is permitted. However, permission to reprint/republish this material for advertising or promotional purposes or for creating new collective works for resale or redistribution must be obtained from the IEEE by writing to pubs-permissions@ieee.org. By choosing to view this document, you agree to all provisions of the copyright laws protecting it.

This paper is posted at ScholarlyCommons. https://repository.upenn.edu/ese_papers/309

For more information, please contact repository@pobox.upenn.edu. 


\title{
Detection of Moisture and Methanol Gas Using a Single Electrospun Tin Oxide Nanofiber
}

\author{
Abstract \\ This letter reports the fabrication of a gas sensor based on a single tin oxide nanofiber made from \\ dimethyldineodecanoate tin using electrospinning and metallorganics decomposition techniques. The \\ fabricated sensor has been used to detect moisture and methanol gas. It showed high sensitivity to both \\ gases and the response times of the complete testing system are in the range of 108-150 s for moisture, \\ and $10-38 \mathrm{~s}$ for methanol gas, respectively.
}

\section{Keywords}

gas detectors, nanotechnology, tin compounds, wire

\section{Comments}

Copyright 2007 IEEE. Reprinted from IEEE Sensors Journal, Volume 7, Issue 9, September 2007, pages 1347-1348.

This material is posted here with permission of the IEEE. Such permission of the IEEE does not in any way imply IEEE endorsement of any of the University of Pennsylvania's products or services. Internal or personal use of this material is permitted. However, permission to reprint/republish this material for advertising or promotional purposes or for creating new collective works for resale or redistribution must be obtained from the IEEE by writing to pubs-permissions@ieee.org. By choosing to view this document, you agree to all provisions of the copyright laws protecting it. 


\title{
Detection of Moisture and Methanol Gas Using a Single Electrospun Tin Oxide Nanofiber
}

\author{
Y. Wang, I. Ramos, and J. J. Santiago-Avilés
}

\begin{abstract}
This letter reports the fabrication of a gas sensor based on a single tin oxide nanofiber made from dimethyldineodecanoate tin using electrospinning and metallorganics decomposition techniques. The fabricated sensor has been used to detect moisture and methanol gas. It showed high sensitivity to both gases and the response times of the complete testing system are in the range of 108-150 s for moisture, and 10-38 s for methanol gas, respectively.
\end{abstract}

Index Terms-Gas detectors, nanotechnology, tin compounds, wire.

\section{INTRODUCTION}

Binary oxide semiconductors have important sensing and optoelectronic applications [1], [2]. Usually, such oxides have a wide band gap and are good insulators in their undoped and stoichiometric state. However, oxygen vacancies leading to nonstoichiometry can easily be formed in their lattice, donate electrons, and greatly increase their conductivity. Their conductivity is also modulated by species chemisorbed on their surface and the subsequent interaction between the chemisorbed species and the nonstoichiometric oxygen vacancies. Tin oxide $\left(\mathrm{SnO}_{2}\right)$ sensors represent some of the early commercialized chemical sensors (the Taguchi sensor) and as such its bulk properties are well known. Usually, the $\mathrm{SnO}_{2}$ sensing element is used as thin films because of their higher surface-to-volume ratio $1 / \mathrm{t}$ ( $t$ is the film thickness) than bulk. With an even higher ratio $2 / \mathrm{r}(r$ is the nanofiber radius, $r \ll t), \mathrm{SnO}_{2}$ nanofibers are expected to have better sensing capabilities (such as higher sensitivity and shorter response time) than thin films. However, $\mathrm{SnO}_{2}$ nanofibers have been fabricated only recently in a limited number of ways, such as thermal decomposition [3], laser ablation [4], template oxidization [5], vapor deposition [6], and electrospinning [7], even though numerous methods have been developed to deposit $\mathrm{SnO}_{2}$ thin film [1], [2]. We fabricated $\mathrm{SnO}_{2}$ nanofibers using electrospinning and metallorganics decomposition (MOD) techniques [7], [8]. The conductivity of our synthesized fiber is highly sensitive to its environment [9], suggesting promising sensing applications. In this letter, we fabricated a gas sensor based on a single electrospun $\mathrm{SnO}_{2}$

Manuscript received March 22, 2007; revised May 3, 2007; accepted May 4, 2007. This work was supported in part by the Natonal Science Foundation under Grant NSF-DMR-0353730 (Penn-UPR Partnership for Research and Education in Materials).

Y. Wang is with the Department of Physics and Electronics, University of Puerto Rico, Humacao, PR 00791 USA. He is also with the Electrical and Systems Engineering Department, University of Pennsylvania, Philadelphia, PA 19104 USA (e-mail: wangyu@ @seas.upenn.edu).

I. Ramos is with the Department of Physics and Electronics, University of Puerto Rico, Humacao, PR 00791 USA (e-mail: iramos@mate. uprh.edu).

J. J. Santiago-Avilés is with the Department of Electrical and Systems Engineering, University of Pennsylvania, Philadelphia, PA 19104 USA (e-mail: santiago@seas.upenn.edu).

Color versions of one or more of the figures in this paper are available online at http://ieeexplore.ieee.org.

Digital Object Identifier 10.1109/JSEN.2007.905045 nanofiber and used it to detect moisture $\left(\mathrm{H}_{2} \mathrm{O}\right)$, and methanol $\left(\mathrm{CH}_{3} \mathrm{OH}\right)$ gases. Although $\mathrm{SnO}_{2}$ nanowires fabricated in other ways have been used to detect $\mathrm{CO}, \mathrm{O}_{2}, \mathrm{CH}_{3} \mathrm{OH}$ and other gases [5], to our knowledge, there have been no such reports in literature using an electrospun $\mathrm{SnO}_{2}$ nanofiber.

\section{EXPERIMENT}

The sensing element of the single $\mathrm{SnO}_{2}$ nanofiber [Fig. 1(a)] was synthesized using electrospinning and MOD techniques. A homogeneous precursor solution with appropriate rheological properties was made from commercial poly (ethylene oxide) (molecular weight 900000 ), chloroform, and dimethyldineodecanoate tin $\left(\mathrm{C}_{22} \mathrm{H}_{44} \mathrm{O}_{4} \mathrm{Sn}\right)$ in a pertinent ratio. Single precursor fibers were electrospun from the solution using a homemade electrospinning setup [7] onto single-crystal silicon wafers with their surface thermally oxidized and patterned with gold contacts. The as-deposited precursor fibers on the $\mathrm{SiO}_{2} / \mathrm{Si}$ substrates were subsequently isothermally decomposed at $600{ }^{\circ} \mathrm{C}$ in air for $2 \mathrm{~h}$, and finally gold wires were bonded to the contacts, as schematically shown in Fig. 1(b). Our previous characterization showed that the synthesized nanofibers were rutile-structured $\mathrm{SnO}_{2}$ [7], [8]. The sensor was tested at room temperature, as shown in Fig. 1(c). During operation, the pressure inside the chamber was maintained about 1.1-1.3 atmosphere by flowing nitrogen $\left(\mathrm{N}_{2}\right)$ gas to prevent the reflux of the ambient atmosphere. The $\mathrm{N}_{2}$ gas was used also to purge the system, to generate a testing gas from its liquid source, and to transport it into the chamber. A Keitheley 6475 A electrometer was used to apply a $0.1 \mathrm{~V}$ bias between two probes and to measure the current $(I)$ and conductance $(G)$. With the fiber size measured under a JOEL JSM-6360 scanning electron microscope (SEM), conductivity $(\sigma)$ was also calculated [9]. After the sensor was loaded, purging $\mathrm{N}_{2}$ was fed directly into the chamber, as well as onto the fiber surface, until $I$ was stabilized. At that time, $\mathrm{N}_{2}$ was directed to go through and bubble deionized water or liquid methanol until $I$ was stabilized at another level. Finally, the $\mathrm{N}_{2}$ gas was redirected to bypass the liquids and flow directly into the chamber.

\section{RESULTS AND DisCUSSION}

Fig. 2 shows the sensor's typical time response to the turn-on and turn-off of $\mathrm{H}_{2} \mathrm{O}$ and $\mathrm{CH}_{3} \mathrm{OH}$ gases with main response parameters listed in Table I. Upon exposure to $\mathrm{H}_{2} \mathrm{O}$ carried by $\mathrm{N}_{2}$ at a higher flow rate, the sensor showed a higher relative $\mathrm{G}$ change and shorter response times, defined as the times it takes $\mathrm{G}$ to change by $90 \%$ of the measured change. Such response is reasonable in that a higher $\mathrm{N}_{2}$ flow rate generates a higher moisture concentration in the chamber, accumulates and ventilates it in a shorter time. In fact, the measured response times are those of the whole testing system, and are affected not only by the sensor's intrinsic response time but also by gas generation, transport and venting times. A higher $\mathrm{N}_{2}$ flow rate decreases the 

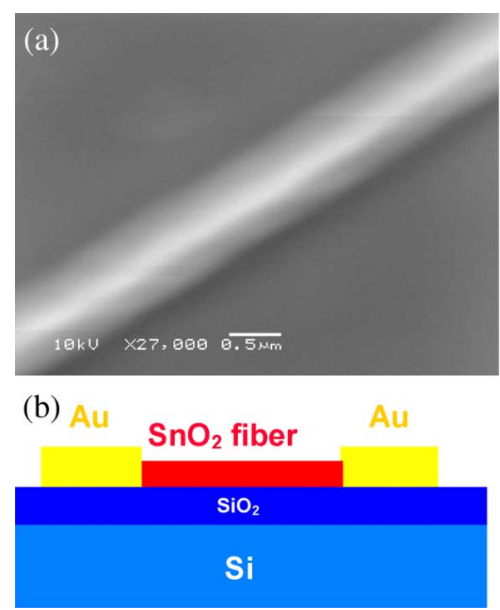

(c)

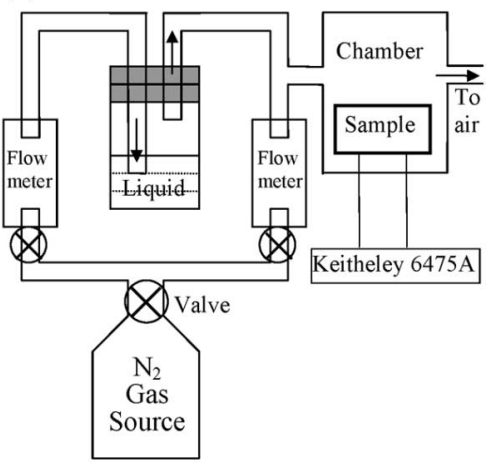

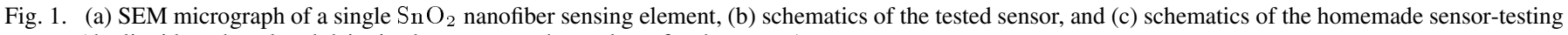
system (the liquid methanol and deionized water were the analytes for these tests).
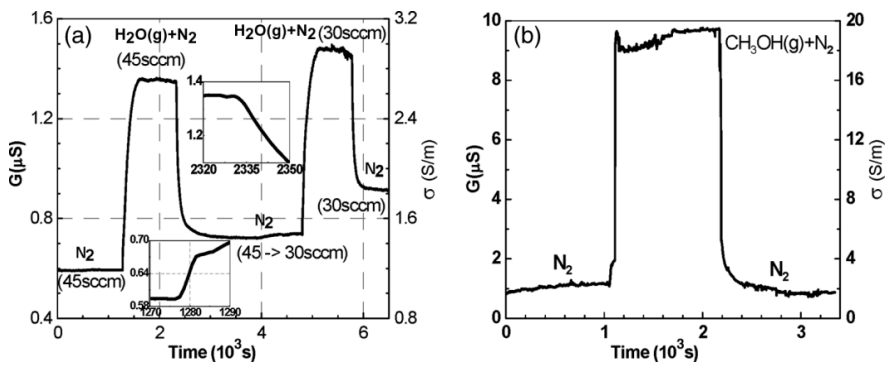

Fig. 2. Response of the sensor to (a) moisture and (b) methanol gas.

TABLE I

MAIN RESPONSE CHARACTERISTICS OF THE SENSOR

\begin{tabular}{cccccc}
\hline $\begin{array}{c}\text { Analyte } \\
\text { Gas }\end{array}$ & $\begin{array}{c}\mathrm{N}_{2} \text { flow rate } \\
\text { (sccm) }\end{array}$ & \multicolumn{2}{c}{$\mathrm{G}($ high $) / \mathrm{G}($ low $)-1$} & \multicolumn{2}{c}{$90 \%$ Response time (s) } \\
Rise & Fall & Rise & Fall \\
\hline $\mathrm{CH}_{3} \mathrm{OH}$ & 45 & $845 \%$ & $845 \%$ & 38 & 10 \\
$\mathrm{H}_{2} \mathrm{O}$ & 45 & $229 \%$ & $88 \%$ & 108 & 150 \\
$\mathrm{H}_{2} \mathrm{O}$ & 30 & $105 \%$ & $62 \%$ & 218 & 187 \\
\hline
\end{tabular}

latter three times. Additionally, $\mathrm{G}$ increased after the first exposure to the moisture, suggesting a not totally reversible change (such as $\mathrm{H}_{2} \mathrm{O}$ adsorption) during that exposure. This may have contributed to the higher $\mathrm{G}$ level during the second exposure than during the first.

With the same $\mathrm{N}_{2}$ flow rate of $45 \mathrm{sccm}, \mathrm{H}_{2} \mathrm{O}$ and $\mathrm{CH}_{3} \mathrm{OH}$ increased $\mathrm{G}$ by $229 \%$ and $845 \%$, respectively. The rise and fall times are 108 and $150 \mathrm{~s}$ for $\mathrm{H}_{2} \mathrm{O}$, and 38 and $10 \mathrm{~s}$ for $\mathrm{CH}_{3} \mathrm{OH}$, respectively. The higher relative $\mathrm{G}$ change and the shorter response times with $\mathrm{CH}_{3} \mathrm{OH}$ do not necessarily mean higher sensitivity to $\mathrm{CH}_{3} \mathrm{OH}$ than to $\mathrm{H}_{2} \mathrm{O}$ since their concentration in the chamber could not be measured. It could, at least partially, be attributed to the higher volatility of $\mathrm{CH}_{3} \mathrm{OH}$, which may have accumulated a higher $\mathrm{CH}_{3} \mathrm{OH}$ concentration in the chamber within a shorter time. The effect is consistent with that of the $\mathrm{N}_{2}$ flow rate on the sensor's responses to moisture.

Although the sensor's response times are not exactly the same as the measured system response times, they cannot be much less than the latter and are expected to be several to tens of seconds. Such response times, although close to the lower limit of the response time range of sensors based on $\mathrm{SnO}_{2}$ thin films [1], are still dictated by surface adsorption and desorption processes, which, after triggered by the introduction and exhaustion of reducing or oxidizing analytes, involve atomic diffusion and surface species migration.

Currently, we are enhancing the testing system in three ways: first, we are adding a vacuum pump to evacuate the chamber and suppress effects of the initial surface state of the fiber and the initial residual gas in the chamber, and to reduce the gas transport time within the system; second, we are using gaseous, as well as more typical, analyte sources (such as $\mathrm{H}_{2}$ and $\mathrm{CO}$ ) to eliminate the gas generation time; and finally, we are using a mass flow controller to monitor the flow rate of analytes and to calculate their concentration in the chamber.

\section{CONCLUSION}

A gas sensor has been fabricated based on a $\mathrm{SnO}_{2}$ nanofiber made through electrospinning and thermal decomposition of $\mathrm{C}_{22} \mathrm{H}_{44} \mathrm{O}_{4} \mathrm{Sn}$, and been used to detect moisture and methanol gases. It shows high sensitivity to both gases and the response times of the complete testing system are 108-150 s for moisture and 10-38 s for methanol gas, respectively.

\section{REFERENCES}

[1] S. Seal and S. Shukla, "Nanocrystalline SnO gas sensors in view of surface reactions and modifications," JOM, vol. 54, no. 9, pp. 35-60, Sep. 2002.

[2] M. Batzill and U. Diebold, "The surface and materials science of tin oxide," Prog. Surf. Sci., vol. 79, no. 2-4, pp. 47-154, Nov. 2005.

[3] C. Xu, G. Xu, Y. Liu, X. Zhao, and G. Wang, "Preparation and characterization of $\mathrm{SnO}_{2}$ nanorods by thermal decomposition of $\mathrm{SnC}_{2} \mathrm{O}_{4}$ precursor," Scripta Mater., vol. 46, no. 11, pp. 789-792, Jun. 2002.

[4] Z. Liu, D. Zhang, S. Han, C. Li, and T. Tang et al., "Laser ablation synthesis and electron transport studies of tin oxide nanowires," $A d v$. Mater., vol. 15, no. 20, pp. 1754-1757, Oct. 2003.

[5] A. Kolmakov, Y. Zhang, G. Cheng, and M. Moskovits, "Detection of $\mathrm{CO}$ and $\mathrm{O}_{2}$ using tin oxide nanowire sensors," Adv. Mater., vol. 15, no. 12, pp. 997-1000, Jun. 2003.

[6] S. Mathur, S. Barth, H. Shen, J.-C. Pyun, and U. Werner, "Size-dependent photoconductance in $\mathrm{SnO}_{2}$ nanowires," Small, vol. 1, no. 7, pp. 713-717, Jul. 2005.

[7] Y. Wang, M. Aponte, N. Leon, I. Ramos, and R. Furlan et al., "Synthesis and characterization of tin oxide microfibres electrospun from a simple precursor solution," Semicond. Sci. Tech., vol. 19, pp. 1057-1060, 2004.

[8] Y. Wang, I. Ramos, and J. Santiago-Avilés, "Synthesis of ultra-fine porous tin oxide fibers and its process characterization," Nanotech., vol. 18, no. 7, pp. 295601-295607, Jul. 2007.

[9] Y. Wang, I. Ramos, and J. Santiago-Avilés, "Electrical characterization of single electrospun porous tin oxide nanofibers," IEEE Trans. Nanotech., submitted for publication. 